\title{
Dorsal Nasal Artery
}

National Cancer Institute

\section{Source}

National Cancer Institute. Dorsal Nasal Artery. NCI Thesaurus. Code C52983.

A vessel arising from the ophthalmic artery that supplies the skin of the root of the nose with oxygenated blood. 